\title{
ARTICLE
}

Translational Therapeutics

\section{Differential effects, on oncogenic pathway signalling, by derivatives of the HNF4 $\alpha$ inhibitor BI6015}

\author{
Jin-Hee Kim ${ }^{1}$, Hyo Jin Eom ${ }^{2}$, GyuTae Lim ${ }^{3,4}$, Sungjin Park ${ }^{5,6}$, Jinhyuk Lee ${ }^{3,4}$, Seungyoon Nam ${ }^{5,6,7}$, Yon Hui Kim ${ }^{8}$ and Jin-Hyun Jeong ${ }^{1}$
}

BACKGROUND: Gastric cancer (GC) is a highly heterogeneous disease with few "targeted" therapeutic options. Previously, we demonstrated involvement of the transcription factor HNF4a in human GC tumours, and the developmental signal mediator, WNT5A, as a prognostic GC biomarker. One previously developed HNF4a antagonist, Bl6015, while not advancing beyond preclinical stages, remains useful for studying GC.

METHODS: Here, we characterised the antineoplastic signalling activity of derivatives of Bl6015, including transfer of the nitro group from the para position, relative to a methyl group on its benzene ring, to the ortho- and meta positions. We assessed binding efficacy, through surface plasmon resonance and docking studies, while biologic activity was assessed by antimitogenic efficacy against a panel of GC cell lines, and dysregulated transcriptomes, followed by pathway and subpathway analysis.

RESULTS: The para derivative of Bl6105 was found substantially more growth inhibitory, and effective, in downregulating numerous oncogenic signal pathways, including the embryonic cascade WNT. The ortho and meta derivatives, however, failed to downregulate WNT or other embryonic signalling pathways, unable to suppress GC growth.

CONCLUSION: Straightforward strategies, employing bioinformatics analyses, to facilitate the effective design and development of "druggable" transcription factor inhibitors, are useful for targeting specific oncogenic signalling pathways, in GC and other cancers.

British Journal of Cancer (2019) 120:488-498; https://doi.org/10.1038/s41416-018-0374-5

\section{BACKGROUND}

Gastric cancer (GC) is the fifth-most prevalent cancer in the world, and the fourth-leading cause of cancer death. ${ }^{1}$ Like most cancers, early detection is paramount, offering the most promising outcomes, via surgical debulking, to minimise residual disease. GC incidence and mortality rates are, by far, the highest in East Asia, largely for unknown reasons. ${ }^{2}$ However, even while GC is relatively rare in most Western countries, population screening is not routine, resulting in delayed diagnosis and poor prognosis (e.g., 5-year survival of merely $30 \%$ in the United States, and 19\% in the United Kingdom). ${ }^{3}$ Consequently, more effective therapies are urgently needed. As GC is a highly heterogeneous malignancy, ${ }^{4}$ personalised medicine (i.e., stratification of patients most likely to respond to specific therapies) is currently the best option to prolong survival. To date, however, most GC clinical trials, of various targeted therapies, have been disappointing. ${ }^{5-7}$

It is now largely accepted that most solid tumours derive from a subpopulation of stem-like cells reliant on embryonic signalling cascades, including the well-known pathway WNT. ${ }^{8}$ Moreover, it has been hypothesised that WNT signalling is activated by the bacterium Helicobacter pylori, a major risk factor for GC. ${ }^{9}$ Clinical studies of WNT inhibitors, however, have thus far been quite limited, and demonstrated only modest antitumour activity, ${ }^{10,11}$ and one possible interpretation is that its downstream effectors (e.g., TCF/LEF, HNF4a) are impinged upon by "cross-talk" from other mitogenic pathways. ${ }^{12,13}$ Thus, while still in its infancy, an increasing strategy is the development of potential antagonists of oncogenic transcription factors. ${ }^{14-16}$

Previously, we demonstrated that a specific subset of GCs (primarily diffuse type) upregulate their metabolism, via an AMPK-HNF4a-Wnt5A transduction cascade, with an HNF4a antagonist, Bl6015 being antitumorigenic, both in vitro and in vivo. ${ }^{17,18}$ The BI6015 compound was originally identified in a high-throughput screen of compounds downregulating green fluorescence in a cell line stably expressing the INS promoter driving the GFP gene, ${ }^{19,20}$ as the INS promoter is well established to possess an HNF4a-binding element, and is strongly upregulated by that transcription factor. That work also showed that Bl6015 downregulated HNF4a protein, and was selectively cytotoxic against Hep3B hepatocellular cancer (HCC) cells (but not primary hepatocytes). A further screen of $\mathrm{NCl}-60$ cancer cells demonstrated Bl6015 cytotoxicity to numerous neoplastic cell lines, but not their normal counterparts. Finally, BI6015 was efficacious in an orthotopic xenograft mouse model, in vivo,

${ }^{1}$ College of Pharmacy, Yonsei Institute of Pharmaceutical Sciences, Yonsei University, Incheon 21983, Korea; ${ }^{2}$ Research and Development Department, Corestem Inc., 24 Pangyo-

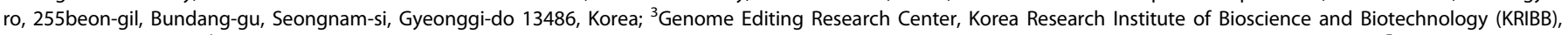

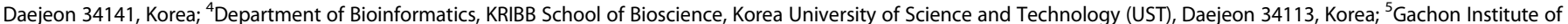

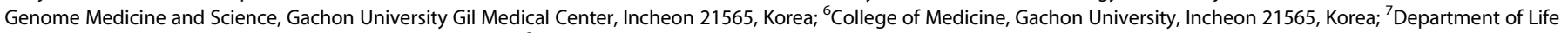

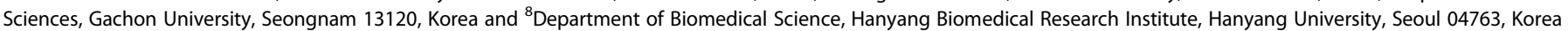
Correspondence: Yon Hui Kim (yonhuisarahkim@gmail.com) or Jin-Hyun Jeong (organicjeong@yonsei.ac.kr)

These authors contributed equally: Jin-Hee Kim, Hyo Jin Eom.

Received: 17 May 2018 Revised: 30 November 2018 Accepted: 7 December 2018

Published online: 22 February 2019 
although liver stenosis was also noted, and the compound exhibited suboptimal pharmacokinetic properties. ${ }^{20}$

In the current study, we devised a straightforward strategy for assessing Bl6015 modifications that might optimise its interactions with the compound-binding site of HNF4a, to increase specificity and druglikeness. Although previously reported studies only assessed only one derivative of B|6015, we examined movement of a nitro group, relative to a methyl group on the Bl6015 benezene ring, from the para to the meta and ortho positions, and possible effects on specific signalling pathways important to improve pharmacokinetic properties. Our results showed that the antimitogenic activity of the parent (para) compound, compared to the derivatives, occurs via potent inhibition of the oncogenic signal mediator WNT. We thereby assert that design of specific transcription factors, via such chemoinformatics and bioinformatics analyses, represents a novel strategy for drug discovery. Also, the ortho and the meta derivatives did not inhibit HNF4a.

\section{MATERIALS AND METHODS}

General chemistry

All reactions sensitive to air or moisture were conducted under a nitrogen atmosphere. Reagents were purchased from SigmaAldrich (St. Louis, MO, USA) and Tokyo Chemical Industry. All the anhydrous solvents were distilled over $\mathrm{CaH}_{2}, \mathrm{P}_{2} \mathrm{O}_{5}$, or $\mathrm{Na} /$ benzophenone, prior to the reaction, unless otherwise stated. Analytical thin-layer chromatography (TLC) was performed using commercial, precoated TLC plates (silicagel 60, F-254, EMD Millipore, Burlington, MA, USA). Spots were then viewed under a ultraviolet (UV) light $(254 \mathrm{~nm})$, or colourising, by charring, after dipping in any of the following solutions: phosphomolybdic acid in ethanol, or potassium permanganate in aqueous solution. Flash column chromatography was performed on silica gel 60 (0.040-0.063 mm, 230-400 mesh, EMD Millipore). Infrared spectra were recorded on an Agilent (Santa Clara, CA, USA) Cary 670 Fourier-transform infrared instrument. Proton nuclear magnetic resonance $\left({ }^{1} \mathrm{H}\right.$ NMR) spectra $\left(\mathrm{CDCl}_{3}, \mathrm{CD}_{3} \mathrm{OD}, \mathrm{D}_{2} \mathrm{O}\right.$, or dimethyl sulfoxide (DMSO)- $d_{6}$ ) were recorded on an Agilent 400-MR (400 $\mathrm{MHz}) .{ }^{1} \mathrm{H}$ NMR data were reported as peak multiplicities: $\mathrm{s}$ for singlet; $d$ for doublet; dd for doublet of doublets; ddd for doublet of doublet of doublets; t for triplet; pseudo t for pseudo triplet; brs for broad singlet; and $\mathrm{m}$ for multiplet. Coupling constants were reported in hertz $(\mathrm{Hz})$. Carbon-13 nuclear magnetic resonance $\left({ }^{13} \mathrm{C}\right.$ NMR) spectra $\left(\mathrm{CDCl}_{3}, \mathrm{CD}_{3} \mathrm{OD}, \mathrm{D}_{2} \mathrm{O}\right.$, or DMSO- $\left.d_{6}\right)$ were recorded on an Agilent $400-\mathrm{MR}(100 \mathrm{MHz})$ instrument. Chemical shifts were reported as ppm $(\delta)$, relative to the solvent peak. Mass spectra were recorded on an electrospray ionization-positive source, in methylene chloride or methanol.

General procedure for the synthesis of sulfonyl chloride (2a and $\mathbf{2 b}$ )

Step (a) Thionyl chloride $(4.2 \mathrm{mmol})$ was added dropwise, over $10 \mathrm{~min}$, to $2-\mathrm{mL}$ water, and cooled to $0^{\circ} \mathrm{C}$. The solution was then allowed to warm to $15^{\circ} \mathrm{C}$, over $16 \mathrm{~h}$. Copper (I) chloride $(0.01 \mathrm{mmol})$ was added to the mixture, and the resultant yellowgreen solution was cooled to $-3{ }^{\circ} \mathrm{C}$. Step (b) Concentrated $\mathrm{HCl}$ $(1 \mathrm{~mL})$ was added, with stirring, to an appropriate aniline $(1 \mathrm{mmol})$, using ice to maintain the temperature of the mixture below $30^{\circ} \mathrm{C}$. The reaction mixture was then cooled to $-5^{\circ} \mathrm{C}$, and a solution of sodium nitrite $(1.1 \mathrm{mmol})$ in water $(0.3 \mathrm{~mL})$ was added drop-wise, over $10 \mathrm{~min}$, maintaining the temperature at -5 to $0^{\circ} \mathrm{C}$. The resultant slurry was cooled to $-2{ }^{\circ} \mathrm{C}$, and stirred for $10 \mathrm{~min}$. Step (c) The slurry from step (b) was cooled to $-5^{\circ} \mathrm{C}$, and added to the solution obtained from step (a), over $30 \mathrm{~min}$. As the reaction proceeded, a solid began to precipitate. When the addition was complete, the reaction mixture was stirred at $0^{\circ} \mathrm{C}$ for $70 \mathrm{~min}$, and the suspended solid collected by vacuum filtration, washed with water, and dried under vacuum, to give the corresponding sulfonyl chlorides, in $52-62 \%$ yields. The sulfonyl chloride products $\mathbf{2} \mathbf{a}$ and $\mathbf{2} \mathbf{b}$ were used for the next step, without further purification (Fig. 1b).

General procedure for the synthesis of sulfonamide (3a, $\mathbf{3} \mathbf{b}$, and $\mathbf{3 c}$ )

A mixture of 2-methyl-1H-benzo $(d)$ imidazole $(1 \mathrm{mmol})$, and an appropriate sulfonyl chloride compound $(1 \mathrm{mmol})$ in $\mathrm{CH}_{3} \mathrm{CN}$ $(5 \mathrm{~mL})$, was stirred at room temperature for $2-5 \mathrm{~h}$. Progress of the reaction was monitored by TLC. After completion of the reaction, the content was poured into ice-cold water $(5 \mathrm{~mL})$, while stirring. The solid was filtered, dried, and purified by recrystallisation, using $\mathrm{MeOH}$ or EtOH to give sulfonamide products $\mathbf{3 a} \mathbf{a} \mathbf{3} \mathbf{b}$, and $3 c$, at $63-88 \%$ yields (Fig. $1 \mathrm{~b}$ ).

\section{2-Methyl-1-((2-methyl-3-nitrophenyl)sulfonyl)-1 $\mathrm{H}$-benzo[ $d]$ imidazole (3a, Bl6015-ortho)}

A white solid; IR (attenuated total reflection (ATR)) $\mathrm{cm}^{-1} 1607$, 1552,$1528 ;{ }^{1} \mathrm{H}$ NMR $\left(400 \mathrm{MHz}, \mathrm{CDCl}_{3}\right) \delta 7.96(\mathrm{~d}, J=8.0 \mathrm{~Hz}, 1 \mathrm{H})$, $7.84(\mathrm{~d}, J=8.0 \mathrm{~Hz}, 1 \mathrm{H}), 7.78(\mathrm{~d}, J=8.0 \mathrm{~Hz}, 1 \mathrm{H}), 7.73(\mathrm{~d}, J=8.0 \mathrm{~Hz}$, $1 \mathrm{H}), 7.51(\mathrm{t}, J=8.0 \mathrm{~Hz}, 1 \mathrm{H}), 7.38(\mathrm{t}, J=8.0 \mathrm{~Hz}, 1 \mathrm{H}), 7.33(\mathrm{t}, J=8.0$ $\mathrm{Hz}, 1 \mathrm{H}), 2.69(\mathrm{~s}, 3 \mathrm{H}), 2.59(\mathrm{~s}, 3 \mathrm{H}) ;{ }^{13} \mathrm{C}$ NMR $\left(100 \mathrm{MHz}, \mathrm{CDCl}_{3}\right) \delta$ 151.27, 149.67, 141.42, 140.42, 133.54, 132.50, 131.59, 129.07, $127.44,125.23,125.16,120.24,113.40,16.98,15.15$; high-resolution mass spectrum (HRMS) calculations for $\mathrm{C}_{15} \mathrm{H}_{13} \mathrm{~N}_{3} \mathrm{O}_{4} \mathrm{~S}[\mathrm{M}-\mathrm{H}]^{-}$: 330.0549; found 330.0545 .

2-Methyl-1-((2-methyl-4-nitrophenyl)sulfonyl)-1 $\mathrm{H}$-benzo[d] imidazole (3b, Bl6015-meta)

A white solid; IR (ATR) $\mathrm{cm}^{-1} 1610,1555,1524 ;{ }^{1} \mathrm{H}$ NMR $(400 \mathrm{MHz}$, $\left.\mathrm{CDCl}_{3}\right) \delta 8.16(\mathrm{~m}, 2 \mathrm{H}), 7.86(\mathrm{~d}, J=9.0 \mathrm{~Hz}, 1 \mathrm{H}), 7.76(\mathrm{~d}, J=8.0 \mathrm{~Hz}$, $1 \mathrm{H}), 7.72(\mathrm{~d}, J=8.0 \mathrm{~Hz}, 1 \mathrm{H}), 7.35(\mathrm{~m}, 2 \mathrm{H}), 2.71(\mathrm{~s}, 3 \mathrm{H}), 2.60(\mathrm{~s}, 3 \mathrm{H})$; ${ }^{13} \mathrm{C}$ NMR $\left(100 \mathrm{MHz}_{1} \mathrm{CDCl}_{3}\right) \delta 151.33,150.45,142.68,141.45,140.62$, $133.45,129.92,127.86,125.19,125.15,121.53,120.22,113.31$, 20.38, 17.02; HRMS calculations for $\mathrm{C}_{15} \mathrm{H}_{13} \mathrm{~N}_{3} \mathrm{O}_{4} \mathrm{~S}[\mathrm{M}-\mathrm{H}]^{-}$: 330.0549; found 330.0543 .

\section{2-Methyl-1-((2-methyl-5-nitrophenyl)sulfonyl)-1H-benzo[d]} imidazole (3c, Bl6015-para)

A white solid; IR (ATR) $\mathrm{cm}^{-1} 1602,1558,1528 ;{ }^{1} \mathrm{H}$ NMR $(400 \mathrm{MHz}$, $\left.\mathrm{CDCl}_{3}\right) \delta 8.85(\mathrm{~d}, J=2.0 \mathrm{~Hz}, 1 \mathrm{H}), 8.38(\mathrm{dd}, J=2.0,8.0 \mathrm{~Hz}, 1 \mathrm{H}), 7.76$ $(\mathrm{d}, J=8.0 \mathrm{~Hz}, 1 \mathrm{H}), 7.70(\mathrm{~d}, J=8.0 \mathrm{~Hz}, 1 \mathrm{H}), 7.52(\mathrm{~d}, J=8.0 \mathrm{~Hz}, 1 \mathrm{H})$, $7.34(\mathrm{~m}, 2 \mathrm{H}), 2.72(\mathrm{~s}, 3 \mathrm{H}), 2.52(\mathrm{~s}, 3 \mathrm{H}) ;{ }^{13} \mathrm{C} \mathrm{NMR}\left(100 \mathrm{MHz}, \mathrm{CDCl}_{3}\right) \delta$ $151.16,146.10,145.50,141.48,138.69,134.54,133.35,128.54$, $125.17,125.07,124.66,120.23,113.27,20.39,17.06$; HRMS calcd for $\mathrm{C}_{15} \mathrm{H}_{13} \mathrm{~N}_{3} \mathrm{O}_{4} \mathrm{~S}[\mathrm{M}+\mathrm{H}]^{+}$: 332.0705; found 332.0703.

\section{Bl6015-to-HNF4a docking studies}

The structures of compounds Bl6015-ortho, Bl6015-meta, and Bl6015-para, as ligands, were constructed using Sybyl-X 2.1.1 software, and energy minimised by the Powell method, using Gasteiger-Marsili charge and the Tripos force field. ${ }^{21}$ The crystal structure of HNF4a was obtained from the Protein Data Bank (PDB code $3 \mathrm{FS1}$ ), ${ }^{22}$ and all crystal water molecules removed. Missing hydrogen atoms were added to the structures. Docking was performed using Surflex-Dock (Sybyl-X 2.1.1, Tripos Inc., St. Louis, MO, USA) ${ }^{23}$ For the protein, the protocol for characterising the binding site of the receptor was generated using a ligand-based approach. All other parameters accepted default settings (Fig. 1a).

AutoDock Vina (v1.1.2), a program for optimising and scoring molecular docking, ${ }^{24}$ was used to assess HNF4a docking to Bl6015-ortho, Bl6015-meta, and Bl6015-para forms. A flexible ligand, MYR (myristic acid), was used to consider docking pose. MYR binding positions (V178, S181, Q185, R226, L236, G237, M252, S256, 1259, Q345, and 1346), of HNF4a, were used for the BI6015 derivatives' docking site. The center of docking used the $\mathrm{Ca}$ coordinate, in each binding residue, of the receptor HNF4a. To obtain the largest number of poses, we set num_modes to 1000 
a

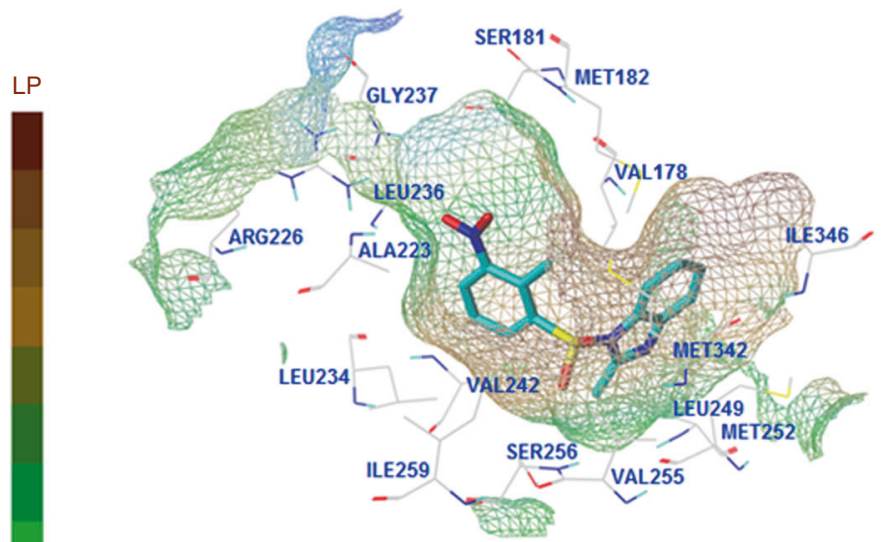

3. BI6015-para

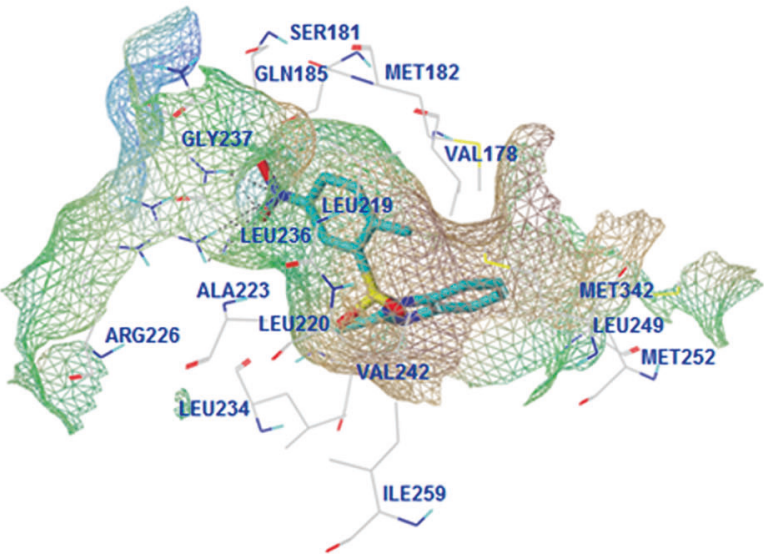

\section{BI6015-meta}

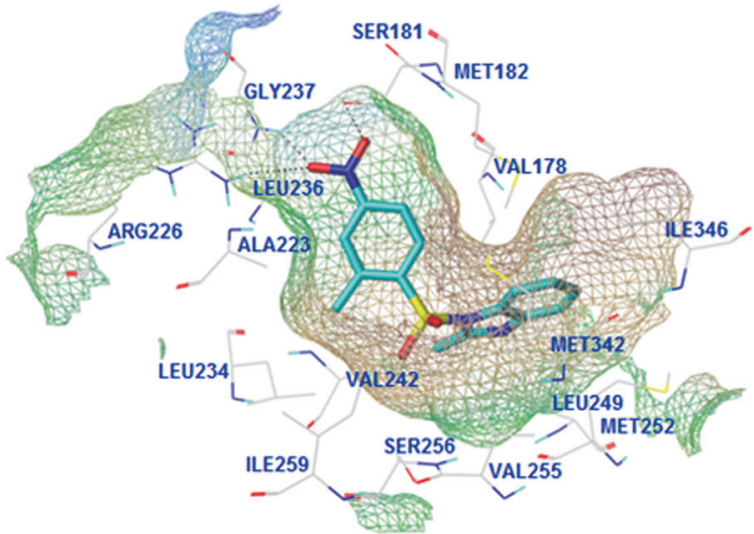

4. BI6015-para b<smiles></smiles>

1a $\left(\mathrm{X}=3-\mathrm{NO}_{2}\right)$

$1 \mathrm{~b}\left(\mathrm{X}=4-\mathrm{NO}_{2}\right)$

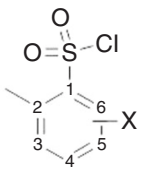

2a $\left(\mathrm{X}=3-\mathrm{NO}_{2}\right)$

$2 \mathbf{b}\left(\mathrm{X}=4-\mathrm{NO}_{2}\right)$

2c $\left(\mathrm{X}=5-\mathrm{NO}_{2}\right)$

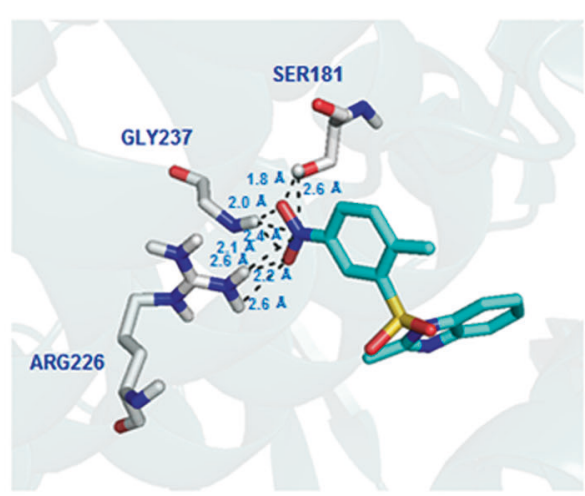

3a $\left(\mathrm{X}=3-\mathrm{NO}_{2}, \mathrm{Bl} 6015\right.$-ortho) 3b $\left(X=4-\mathrm{NO}_{2}, \mathrm{Bl} 6015-\right.$ meta $)$ 3c $\left(\mathrm{X}=5-\mathrm{NO}_{2}, \mathrm{Bl6015}\right.$-para)

Fig. 1 Binding modes and synthesis of BI6015 derivates. a The proposed binding modes of BI6015-ortho (3a), BI6015-meta (3b), and BI6015para (3c) forms in the binding pocket of human HNF4 $\alpha$ (PDB code 3FS1), with key amino acid residues shown. Hydrogen bonds are denoted as black dotted lines. (1) Each part of the ligand-binding pocket for the ortho-nitro-substituted BI6015 3a is represented as a lipophilic potential surface. (2) Each part of the ligand-binding pocket for the meta-nitro-substituted $\mathbf{3 b}$ is represented as a lipophilic potential surface. (3) Each part of the HNF4 $\alpha$ ligand-binding pocket for para-nitro-substituted 3c is represented as a lipophilic potential surface. (4) The binding site for para-nitro-substituted 3c, as an HNF4 $\alpha$ ligand, is in ribbon cartoon. Amino acid residues interacting via hydrogen bonds are labeled. b Reagents and conditions: (a) (i) $\mathrm{HCl}, \mathrm{H}_{2} \mathrm{O}, \mathrm{NaNO}_{2}$, (ii) $\mathrm{SOCl}_{2}, \mathrm{H}_{2} \mathrm{O}, \mathrm{CuCl}$; (b) 2-methyl-1H-benzo[d]imidazole, $\mathrm{CH}_{3} \mathrm{CN}$

and energy_range to 50. A $15 \AA$ docking box around the $\mathrm{Ca}$ coordinate was defined. The docked ligands, obtained by $\mathrm{Ca}$ docking, were then clustered using $\mathrm{CHARMM}^{25}$ on the center of mass (COM), and the structure with the lowest energy was selected for each cluster. The cluster radius was $4 \AA$. The predicted binding energy was calculated as $\mathrm{kcal} / \mathrm{mol}$, and the free energy, depending on the number of ligands in the cluster, was calculated as "lowest energy $+(-k T \ln N)$."

Cell culture experiments

All GC cell lines (AGS, MKN45, MKN1, SNU16, SNU668, SNU601, SNU620, NCl-N87, NCC24, NCC59, and SNU1750) were obtained from the American Type Culture Collection (Manassas, VA, USA), and grown in RPMI-1640 (Invitrogen, Carlsbad, CA, USA) and 10\% foetal calf serum (Hyclone, Logan, UT, USA), at $37^{\circ} \mathrm{C}$, under $5 \%$ $\mathrm{CO}_{2}$. Cells $\left(2.5 \times 10^{5}\right)$ were seeded and grown to $70-80 \%$ confluence and treated with DMSO, 5 or $10 \mu \mathrm{M}$ para-BI6015, ortho-BI6015, or meta-BI6015 for $48 \mathrm{~h}$, and cell viability was determined by 3-[4,5-dimethylthiazol-2-yl]-2,5 diphenyl tetrazolium bromide (MTT) assay (Sigma). For Western blot, cells were washed twice with phosphate-buffered saline + Tween-20, lysed in $20 \mathrm{mM}$ Tris ( $\mathrm{pH} 7.4$ ), $250 \mathrm{mM} \mathrm{NaCl}, 2 \mathrm{mM}$ EDTA, and $1 \%$ Triton X-100 buffer, using total protein harvested following treatment. Each cell line was prepared at $n=3$, using a pool of three samples per cell line prepared at $50 \mu \mathrm{g}$ per lane, electrophoresed through sodium dodecyl sulfate-polyacrylamide 
gel electrophoresis gels, transferred to PVDF membranes, and treated with antibodies against HNF4a, WNT5A, or $\beta$-actin (Cell Signaling Technology).

The following human GC cell lines were used within 6 months of tissue resuscitation: NCl-N87, AGS (ATCC), MKN45 (RIKEN), SNU484, SNU-601, and SNU-1967 (KCLB), cultured in RPMI-1640 (HyClone), and $10 \%$ foetal calf serum (HyClone) at $37^{\circ} \mathrm{C}$ under $5 \% \mathrm{CO}_{2}$. Cell line identities were validated by short tandem repeat profiling (ATCC, RIKEN, and/or KCLB).

\section{Reporter (luciferase) assay}

Luciferase reporter assays were performed using SNU1750, AGS, MKN45, NCC24, NCC59, and NCl-N87 cells stably transfected with a TCF/LEF reporter assay system (Qiagen Sciences, Hilden, Germany). Transfected cells were then treated with $2-\mu \mathrm{M}$ para-Bl6015, orthoBl6015, or meta-Bl6015 (each cell line performed at $n=3$ ). The positive control was a constitutively expressed green fluorescent protein (GFP) construct, and the negative control was a minimal promoter GFP reporter. Cells were lysed with passive lysis buffer, and transferred to 96-well white opaque flat-bottom plates, to assess luciferase activity via a Dual-Luciferase reporter assay system (Promega, Madison, WI, USA) and VICTOR Light (Perkin Elmer, Waltham, MA, USA). Luciferase activity was measured on days 2 and 4 , post-reporter transfection.

Statistical analysis

For individual gene experiments, $p<0.05$ was considered statistically significant, based on Student's $t$ - or $z$ tests, when comparing two groups (replicates $n=3$ per group) (Fig. 4).

Gene expression assessments and analysis

Following the above-mentioned drug treatments (AGS, SNU216, SNU601, SNU668, and MKN1 at 10- $\mu$ M para-Bl6015, ortho-BI6015, or meta-Bl6015 for $48 \mathrm{~h}$; each cell line performed at $n=3$ ), total cellular messenger RNA (RNA) was isolated, using RNeasy kits (Qiagen), reverse transcribed, and hybridized to gene expression microarrays (Thermo Fisher Scientific), using a procedure we published previously. ${ }^{17}$ Gene expression was then assessed by unsupervised hierarchical clustering, with results visualised using TreeView. ${ }^{26}$ Gene set enrichment analysis (GSEA) ${ }^{27}$ was then used for pathway analysis of the gene expression results.

Hierarchical clustering and gene set enrichment analysis Gene expression profiles were stratified by unsupervised hierarchical clustering, with results depicted using R. GSEA ${ }^{27}$ was then used for pathway analysis of the genes found significantly misexpressed.

\section{Subpathway analysis}

Subpathway analyses were performed using our published algorithm, $\mathrm{PATHOME},{ }^{28}$ designed to statistically discover differentially expressed subpathways, using KEGG (Kyoto Encyclopedia of Genes and Genomes) ${ }^{29}$ as its prior knowledge of pathway structure. This algorithm requires gene expression levels of both control vs. case groups. Therefore, we performed subpathway analysis on each of the three para-, ortho-, and meta-treated cell line (AGS, SNU216, SNU601, SNU668, and MKN1) datasets, as the case group, and the DMSO-treated cell lines, as the control group. The statistical significance cut-off was set to 0.05. After that, we distinguished genes that were commonly or uniquely identified, in each subpathway analysis, by merging the results of each subpathway analysis, based on their unique symbols. Because the interaction types (e.g., inhibition, activation), between two neighboring genes, were conserved (as registered in KEGG), we exported the merged results to Cytoscape, ${ }^{30}$ to generate a network diagram. Among commonly identified genes, we performed a statistical test, one-way analysis of variance (ANOVA), with $p$ value cut-offs set to 0.05 , to identify genes differentially dysregulated for each treatment group.
Survival analysis

Clinical dataset. Clinical censoring data (including race), for survival analysis, was obtained from a The Cancer Genome Atlas $(T C G A)^{31}$ stomach adenocarcinoma (STAD) (i.e., TCGA STAD) gene expression database (originally determined by RNA-sequencing (IlluminaHiseq, version: 2015-02-24)), downloaded from the UCSC Cancer Genomics Browser, ${ }^{32,31}$ in cBio Portal. ${ }^{33}$ The number of live, deceased, or absent patient samples, available for overall survival (OS) and gene mRNA expression, was 368.

For each gene previously found statistically significant by ANOVA, we calculated the 1st (bottom 25\%) and 3rd (upper 25\%) quantile values, from the 368 samples. These quantiles were then used for dividing the TCGA Asian samples (77 samples) into their respective bottom and upper $25 \%$ groups. The mRNA expression level of the bottom $25 \%$ was less than the 1 st quantile value, and that of upper $25 \%$ was greater than the 3rd quantile value. We then compared the two groups, ${ }^{34}$ using a log-rank test (Fig. 6).

\section{RESULTS}

Protein-ligand interaction modelling for predicting mode of binding inhibition

Molecular docking studies were performed to extensively probe structure-activity relationships, and possible binding modes, of the three Bl6015 derivatives, within the HNF4a ligand-binding pocket. Specifically, we hypothesised that relocation of a nitro group, from the para position, relative to a methyl group on the Bl6015 benzene ring, to the ortho and meta positions, could alter HNF4a downstream signalling, and possibly increase ADME (i.e., Absorption, Distribution, Metabolism, and Excretion) properties of the drug. ${ }^{35,36}$ These Bl6015 derivatives, as ligands, were docked into the ligand-binding pocket of human HNF4a (PDB code $3 F S 1)^{21}$ as a receptor, using Surlflex-Dock (SYBYL-X 2.1.1) (Fig. 1).

A binding pose comparison of the Bl6015-ortho, BI6015-meta, and Bl6015-para compounds, within the ligand-binding pocket of human HNF4a, is shown in Fig. 1a. The protein ligand-binding site is represented by Connolly surface amino acids, colour-coded according to lipophilicity. The brown areas are lipophilic, the blue areas hydrophilic, and the green areas neutral. Side chains of the key amino acid residues, which may participate in hydrogen bonding with the Bl6015 derivatives, are shown. Hydrogen bonds between the ligand (i.e., the Bl6015 derivatives) and the side chains of HNF4a amino acids are represented by black-dotted lines.

Analysis of Bl6015 docking revealed that its phenyl ring-bound nitro group should be buried, to accept hydrogen bonds from the HNF4a ligand-binding domain, on its lipophilic surface. These results showed that the ortho-nitro and meta-nitro substitutions caused a steric clash that interfered with BI6015-ortho and BI6015meta derivative binding, whereas the para-nitro (parent compound) allowed interaction of the nitro group, via strong hydrogen bonding with HNF4a. The correlation in ribbon cartoon between substituted Bl6015-para and the key amino acid residues in the HNF4a-binding site is depicted in Fig. 1a, showing an extensive hydrogen bonding interaction of the nitro group of Bl6015-para and the amine or hydroxyl groups of three amino acid residues (SER181, ARG226, and GLY237), within the ligand-binding pocket of human HNF4a.

We also found that the Bl6015-para derivative had the most energy-stable structure. Figure 2 shows the docking energy results for BI6015 derivative binding to the HNF4a ligandbinding pocket, as determined using Autodock Vina 1.1.2. That analysis successfully identified numerous docking results as changes in the poses of Bl6015 (see "Bl6015-to-HNF4a Docking Studies," in the Materials and methods). Docked compounds were clustered according to similar poses and positions, and the clusters having the lowest binding energies then selected. For each structure, Bl6015 derivatives are shown in the form of 


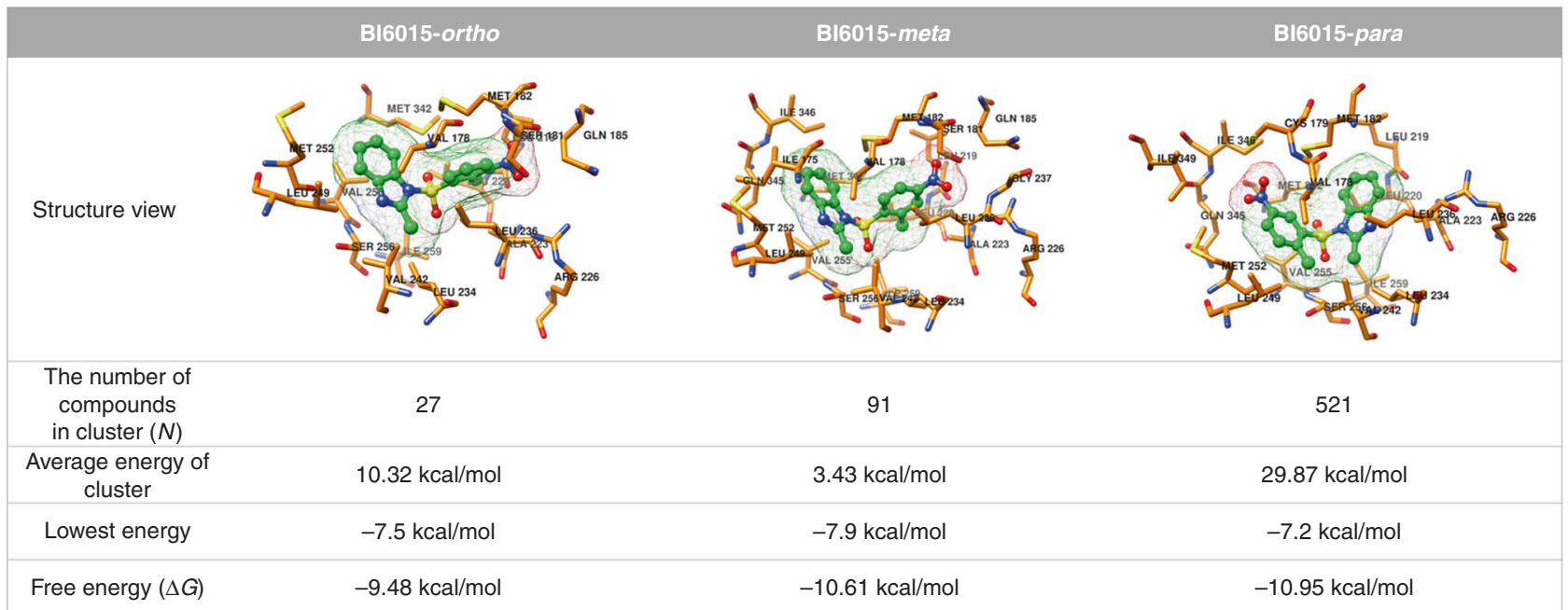

Fig. 2 Docking results for Bl6015-ortho, Bl6015-meta, and Bl6015-para forms. The Bl6015-ortho, Bl6015-meta, and BI6015-para forms are represented by green "balls and sticks," and a mesh surface. The residues of HNF4 $\alpha$ are indicated by an orange stick. HNF4 $\alpha$ residue numbers are shown in black. The number of compounds in each cluster represents the number of similarly posed, docked Bl6015 derivatives with the lowest energies. All structures were drawn using the Chimera software

green balls-and-sticks, and their HNF4a-interacting residues represented by orange sticks (Fig. 2).

In Fig. 2, "The number of compounds in cluster" is the final number of ligands in the selected cluster groups, and the number of docked Bl6015-ortho, BI6015-meta, and Bl6015-para derivatives were 27,91 , and 521, respectively, showing the BI6015-para cluster group to have the most similar poses within the binding pocket. The average energy of the clusters was $10.32 \mathrm{kcal} / \mathrm{mol}$ for the ortho form, $3.43 \mathrm{kcal} / \mathrm{mol}$ for the meta form, and $29.87 \mathrm{kcal} / \mathrm{mol}$ for the para form. However, the ortho form showed a large energy deviation between the Bl6015 ligands forming the cluster, while the energy deviation of the meta form ligands was small. The average energy of the docked para form was relatively higher than the others, because of the large number (521) of ligands forming the cluster, and the fact that their distribution did not converge to the binding site. The ligand with the lowest binding energy was Bl6015-meta at -7.9 $\mathrm{kcal} / \mathrm{mol}$, and thus could be judged as more structurally stable than the other forms. However, when the free energy, considering entropy, was measured, the B16015-para form had the lowest free energy, $-10.95 \mathrm{kcal} / \mathrm{mol}$, indicating it to be the energy-stable, at the HNF4a ligand-binding site, of the three derivatives, thus forming stronger bonds.

\section{Chemistry}

For the mechanistic study of Bl6015 derivatives binding to the pocket of HNF4a, we focused on the design and synthesis of structurally related Bl6015 derivatives, in which a nitro $\left(\mathrm{NO}_{2}\right)$ group is, respectively, relocated to the ortho (3a) meta (3b) positions, as opposed to the parent compound, with the nitro group at the para position (3c, Bl6015), ${ }^{37}$ relative to a methyl group, on the benzene ring (Fig. 1b).

2-Methyl-3-nitrobenzenesulfonyl chloride (2a) and 2-methyl-4nitrobenzenesulfonyl chloride (2b) were synthesized from commercially available 2-methyl-3-nitro aniline and 2-methyl-4-nitro aniline, respectively, using aqueous acidic conditions, via a diazonium ion intermediate, in the presence of copper salts, with thionyl chloride as the sulfur dioxide $\left(\mathrm{SO}_{2}\right)$ source. After conversion of the amine group to sulfonyl chloride, on the phenyl ring, the treatment of an appropriate sulfonyl chloride (2a or $\mathbf{2 b}$ ) with 2-methyl-1H-benzo[d]imidazole, in acetonitrile, afforded the desired 3- $\mathrm{NO}_{2}$ (3a, BI6015-ortho) or 4- $\mathrm{NO}_{2}$ (3b, BI6015-meta) derivative. Also, treatment of 2-methyl- $1 \mathrm{H}$-benzo[d]imidazole with commercially available 2-methyl-5-nitrobenzenesulfonyl chloride (2c), in acetonitrile, gave the parent compound (3c, Bl6015-para).

Surface plasmon resonance: protein-ligand interactions We next performed surface plasmon resonance (SPR) to analyse protein-ligand interactions, and kinetic constants, between HNF4a and the Bl6015 derivatives, including determination of the on-rate $\left(k_{\mathrm{a}}\right)$, off-rate $\left(k_{\mathrm{d}}\right)$, and dissociation constant $\left(K_{\mathrm{D}}\right)$. Of the three compounds, Bl6015-para had the lowest $k_{\mathrm{d}}$ and $K_{\mathrm{D}}$ values (0.00165 and $29.8 \mu \mathrm{M}$, respectively), compared to Bl6015-meta and Bl6015-ortho (Fig. 3), and would thus be predicted to most affect HNF4a and its downstream signalling.

Experimental validation of the three (BI6015-para and its two derivative) compounds. For validating the in silico and SPR findings described above, we treated six diverse GC cell lines with parental Bl6015 (para-nitro), and its ortho and meta derivatives. Using 96-well plates, $2 \times 10^{5}$ cells were treated for $48 \mathrm{~h}$ with 5 or $10 \mu \mathrm{M}$ of each Bl6015 derivative, and then the viability was determined by MTT assay. As shown in Fig. 4a, in agreement with predicted and measured binding properties, the parent compound (para nitro) caused the greatest loss of viability, at nearly $100 \%$, of SNU620 and AGS GC cells, at $~ 90 \%$, of SNU216 cells, but slightly less so (70-75\%), of the remaining three GC lines (SNU601, SNU668, and MKN1). These assays demonstrated the potency of this compound. Although not shown here, we previously demonstrated negligible cytotoxicity of Bl6015-para toward normal gastric mucous columnar cells, ${ }^{17}$ similar to another report of Bl6015 treatment of numerous normal epithelial cell lines. $^{20}$

Since Bl6015 was previously demonstrated as antitumorigenic against HCC, largely via its destabilising effects on HNF4a, ${ }^{20}$ we next examined parental (para) Bl6015, and its meta and ortho analogs for such properties, against five GC cells, AGS (mid-level HNF4a expression), and SNU601, SNU668, SNU216, and SNU620 (low HNF4a expression). These results largely supported the cell viability assays of Fig. $4 \mathrm{a}$, showing that the cells most sensitive to Bl6015 had the greatest losses of HNF4a (Fig. 4b and SI, Figure S1). Analogously, those with less endogenous HNF4a (SNU601, MKN1, SNU216, and SNU668, Fig. 4 and Supplementary Figure S1), despite further protein loss, were less growth inhibited. However, loss of WNT5A protein expression was greater by para-BI6015, in comparison to its meta and ortho analogs (Fig. 4b), thus showing 


\begin{tabular}{|c|c|c|c|c|}
\hline Compound & Product structure & $k_{\mathrm{a}}\left(\mathrm{M}^{-1} \mathrm{~S}^{-1}\right)$ & $k_{\mathrm{d}}\left(\mathrm{S}^{-1}\right)$ & $K_{\mathrm{D}}(\mathrm{M})$ \\
\hline Ortho & & $149 \pm 4$ & $\begin{array}{c}0.00963 \\
\pm 0.00007\end{array}$ & $65 \pm 2 \mu \mathrm{M}$ \\
\hline Para & & $55 \pm 1$ & $\begin{array}{c}0.00165 \\
\pm 0.00003\end{array}$ & $29.8 \pm 0.5 \mu \mathrm{M}$ \\
\hline Meta & & $20.4 \pm 0.7$ & $\begin{array}{c}0.00765 \\
\pm 0.00004\end{array}$ & $380 \pm 10 \mu \mathrm{M}$ \\
\hline
\end{tabular}

Fig. 3 B|6015-ortho, Bl6015-meta, and BI6015-para $K_{\mathrm{D}}$ values, as determined by surface plasmon resonance

downregulation of not only HNF4a but also its downstream target genes, including WNT5A.

In vitro inhibition of WNT signalling by Bl6015-para, and its two derivative compounds. To validate our previous findings of the importance of a WNT5A/HNF4a signalling cascade, to GC progression, ${ }^{17}$ we stably transfected GC cell lines (AGS, SNU1750, MKN45, NCC24, NCl-N87, and NCC59) with a TCF/LEF-luc reporter or empty vector, to quantify possible WNT pathway downregulation. Specifically, selection of these GC cell lines was based on low-to-high RhoA protein expression levels, and an established WNT pathway-responsive reporter system. ${ }^{38}$ Each GC cell line was treated with $2-\mu \mathrm{M}$ Bl6015, and its derivatives, and luciferase activity subsequently measured on days 2 and 4, post-reporter transfection. As shown in Fig. 4c, $60 \%$ (NCI-N87) to $95 \%$ (AGS, SNU1750, NCC24) to $100 \%$ (NCC59) luciferase activity was inhibited in five of the six GC cell lines, using the parental para-BI6015. However, in the treatment of the ortho and meta compounds (Fig. 4b, c), none of these five cells demonstrated significant WNT inhibition, or WNT5A downregulation. One GC cell line, MKN45, underwent no drug inhibition (by any Bl6015 analog) of WNT signalling, again demonstrating the challenges in drug development for this highly heterogeneous malignancy. ${ }^{39}$ These data do, however, validate our previous finding that the TCF/LEF reporter assay system is a sensitive HNF4a drug readout, as shown in Fig. 4b, and its downstream pathway, in cross-talk with other HNF4a targets (Figs. 4b, c). While WNT5A was one HNF4a target downregulated by para-BI6015, we cannot conclude, however, that loss of TCF/LEF reporter activity was strictly due to loss of WNT5A, as this assay merely measures total WNT activity, and cannot discriminate between specific WNT isoforms.

Parental Bl6015 (-para) treatment induces differential gene dysregulation, in inhibiting the WNT signalling pathway. We next performed correlation clustering analysis of BI6015-treated GC cells, based on gene expression microarray results. As shown in Fig. 5a, cells treated with the parental (para position) compound correlated, at the molecular level, into one cluster (left columns, Fig. 5a). However, treatment with vehicle (DMSO), or the two substituents (ortho and meta nitro derivatives), did not change cell-to-cell transcriptomes, and thus these cells merely clustered among themselves, irrespective of drug treatment (DMSO or meta or ortho compounds).

Since clustering analysis showed that the para-treated cell lines correlated at the molecular level, we then compared these cells with those treated with the other Bl6015 derivatives, using GSEA, with hallmark gene sets from MSigDB. GSEA showed that para-compound-treated cell lines effectively downregulated the WNT, Notch, and other oncogenic signalling pathways (Fig. 5b), compared to GC cell lines treated with the other Bl6015 derivatives.
With clustering and GSEA analyses, we found that paraBl6015-treated cell lines correlated in gene expression, and various functional contexts, including suppression of the WNT and Notch embryonic signalling pathways. We then performed subpathway analysis to identify distinctly dysregulated signalling subpathways and genes, using our previously developed tool, PATHOME, ${ }^{28}$ which enables delineation of statistically significant differential expression patterns, along specific subpathways. We then merged the resulting differentially expressed subpathways, of the three experimental groups (AGS, MKN-1, and SNU601 GC cell lines treated with 10- $\mu$ M BI6015 para, ortho, and meta derivatives), compared to the DMSO-treated control group, to distinguish commonly vs. uniquely dysregulated genes. We first sought gene expression patterns, commonly identified among cell lines treated with each specific compound, by performing a statistical test, one-way ANOVA.

Based on the above determinations, 23 genes were found as commonly differentially expressed among the para-treated GC cell lines, compared to the other cell lines $(p<0.05$, Supplementary Figure S2 and Supplementary Table S1). Among these 23 genes, in para-treated cell lines, CTNNB1 and TCF7, members of the WNT signalling pathway (Supplementary Table S2), showed significantly dysregulated (mostly downregulated) patterns, compared to the DMSO-treated and the orthoBl6015- and meta-Bl6015-treated cell lines. Then, we sought dysregulated patterns among genes belonging to subpathways found statistically significant by PATHOME, to identify which genes and subpathways were affected, with merged subpathways presented as a network diagram (Fig. 5c; for all uniquely identified genes of each treatment group, see Supplementary Figure S3).

Uniquely discovered genes were then arranged in the order of para-BI6015-, meta-BI6015-, and ortho-BI6015-treated cell lines (clockwise from the upper left in Fig. 5c), with commonly identified genes arranged in the center of the network. The para (parental Bl6015)-treated cell lines showed more dysregulated patterns of genes than the ortho-Bl6015- and meta-Bl6015treated cell lines (Supplementary Figure S3). In particular, the WNT signalling pathway of the para-BI6015-treated cell lines had a greater number of dysregulated (primarily downregulated) genes (Fig. 5c, marked as circle \# 1). Based on this network analysis, the WNT signalling pathway of the para-BI6015-treated cell lines showed highly dysregulated gene expression patterns, in accord with our previous reports, ${ }^{17,18}$ showing that the HNF4a/WNT signalling pathway plays an important role in GC, thus representing a strong therapeutic target.

In addition, using The Cancer Genome Atlas STomach ADenocarcinoma (TCGA-STAD) Asian patient dataset, we performed survival analysis for each gene found differentially expressed, in the para-Bl6015-treated group, compared to the other groups (for group stratification criteria, see the Materials and methods). As shown in Fig. 6, the WNT pathway genes FZD2, 


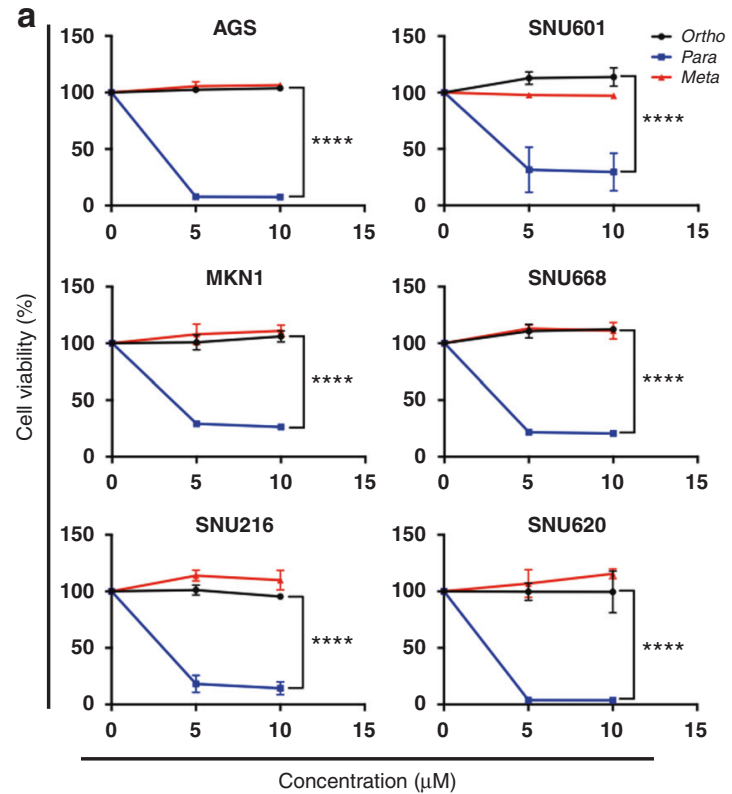

C

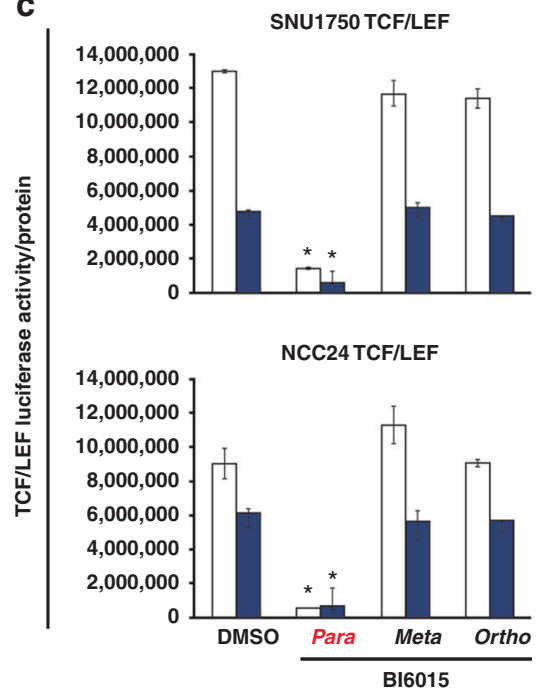

b
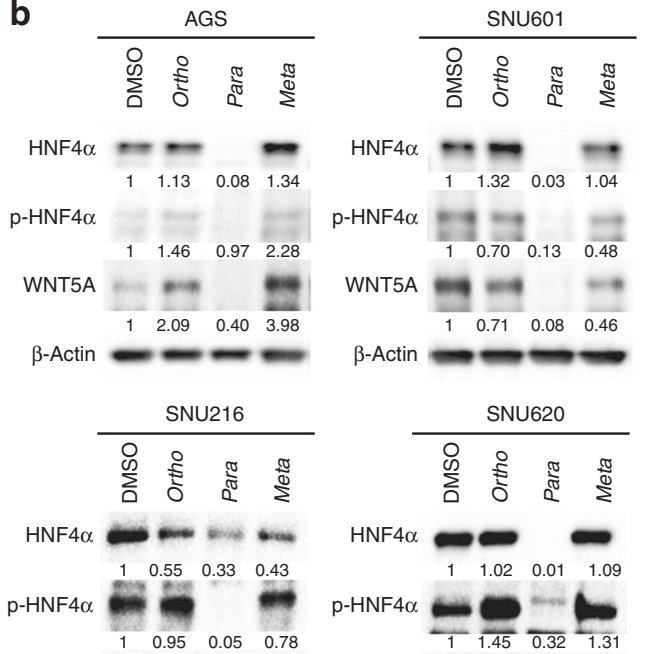

WNT5A

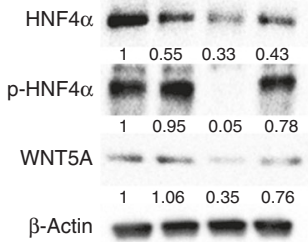

$\begin{array}{llll}1 & 1.06 & 0.35 & 0.76\end{array}$

$\beta$-Actin

AGS TCF/LEF

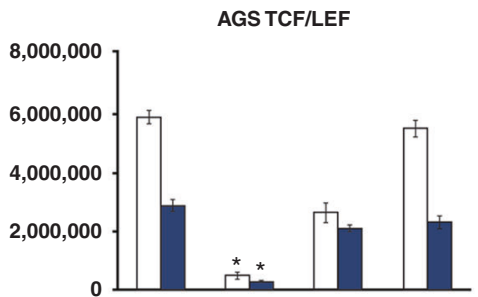

NCC59 TCF/LEF

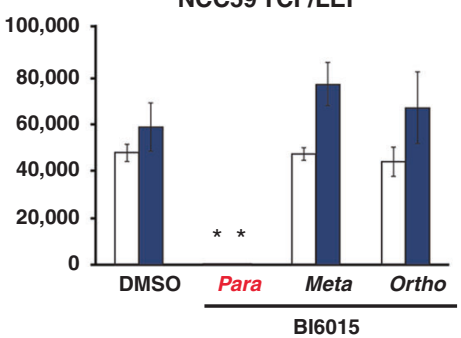

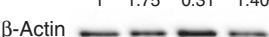

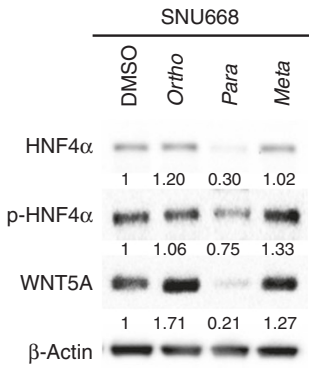

$\beta$-Actin $\longrightarrow$
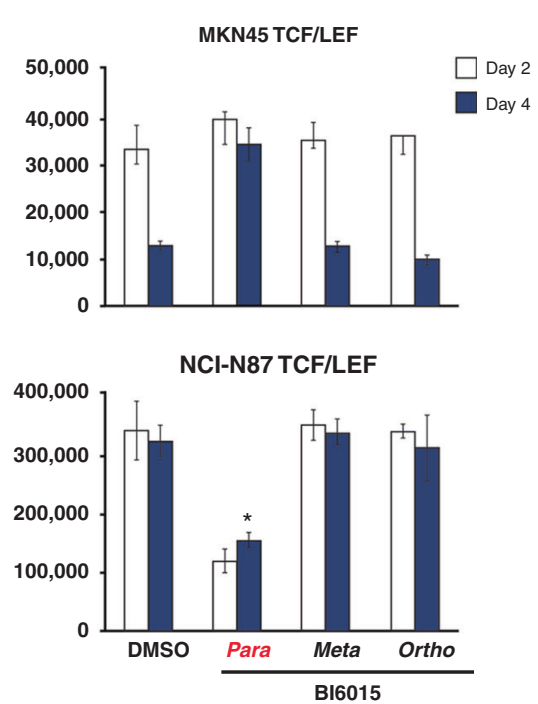

Fig. 4 Bl6015 inhibition of gastric cancer (GC) cell growth and WNT signalling. a Cell viability assays were performed in the treatment of BI6015. Six cell lines were selected based on their HNF4 $\alpha$ and RhoA protein expression levels, AGS (mid-level RhoA expression), SNU601, SNU668, SNU216, and SNU620 (high-level expression), and MKN1 (low-level expression). The cell lines were treated with 5 and 10 $\mu$ M of the three Bl6015 derivatives. b Western blot analysis showing HNF4 $\alpha$ and WNT5A protein levels, and the five GC cell lines were treated with the three Bl6015 derivatives for $48 \mathrm{~h}$. c Monitoring of WNT signalling activity, using a TCF/LEF-luc reporter luciferase assay, followed by $2 \mu \mathrm{M}$ of the three BI6015 derivatives, for 48 or 96h, in six GC cell lines (SNU1750-, AGS-, MKN45-, NCC24-, NCC59-, NCI-N87-TCF/LEF). Because of the cell viability within the GC cell line panel, ${ }^{17}$ few cell lines failed to meet the transfection quality to perform TCF/LEF reporter assay. Therefore, we showed different cell lines to explain the study $\left({ }^{*} p<0.05\right.$ and $\left.{ }^{* * * *} p<0.005\right)$ (error bar: the standard error of the mean)

FZD8, and CSNK1A1 were found significant to GC OS, as determined by log-rank test, with $p$ values of $0.0352,0.0011$, and 0.001 , respectively.

\section{DISCUSSION}

In this study, we extensively characterised the efficacy and pharmacology of Bl6015, an inhibitor of the transcription factor, HNF4a, a "master" signal mediator we $\mathrm{w}^{17,18}$ and others ${ }^{40,41}$ previously showed to be downregulated by the metabolic sensor, AMPK. HNF4a is most highly expressed in the liver, kidney, intestine, and pancreas, where its dysregulation is strongly linked to type 2 diabetes, due to its downregulation of the INS promoter, via binding to an alternative promoter. $^{42}$ By exploiting that relationship, using an INS reporter in a high-throughput compound screen, ${ }^{19}$ an HNF4a inhibitor, Bl6015, was discovered; Bl6015 was also selectively cytotoxic to numerous cancer (but not normal) cells. However, while an in vivo study of Bl6015 in murine liver cancer showed antitumour efficacy, shortcomings included liver stenosis and suboptimal bioavailability. ${ }^{20}$

Previous reports indicate that two Wnt genes, FZD2 and FZD8, play roles in the metastasis-promoting epithelial-mesenchymal transition. ${ }^{43,44}$ Moreover, CSNK1A1 is recognised as a tumour suppressor gene, and its dysregulated gene expression-associated transcriptome very likely drives cancer progression. ${ }^{45,46}$ Considering those reports, downregulation of $F Z D 2$ and $F Z D 8$, in parallel 
a

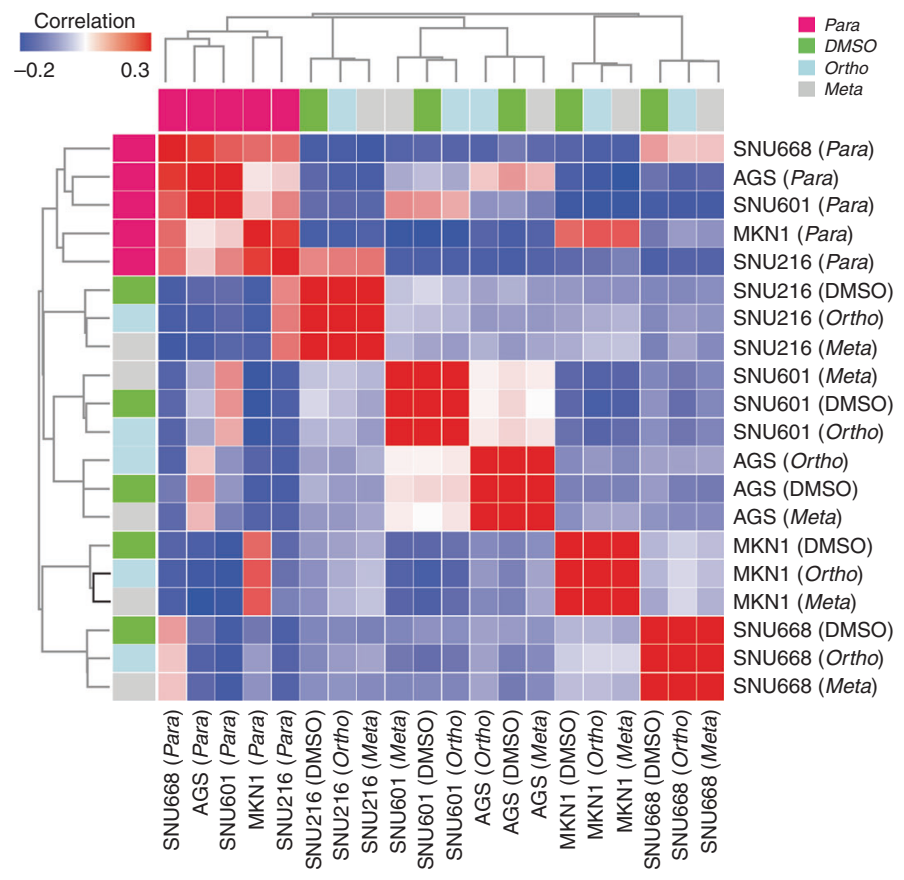

b

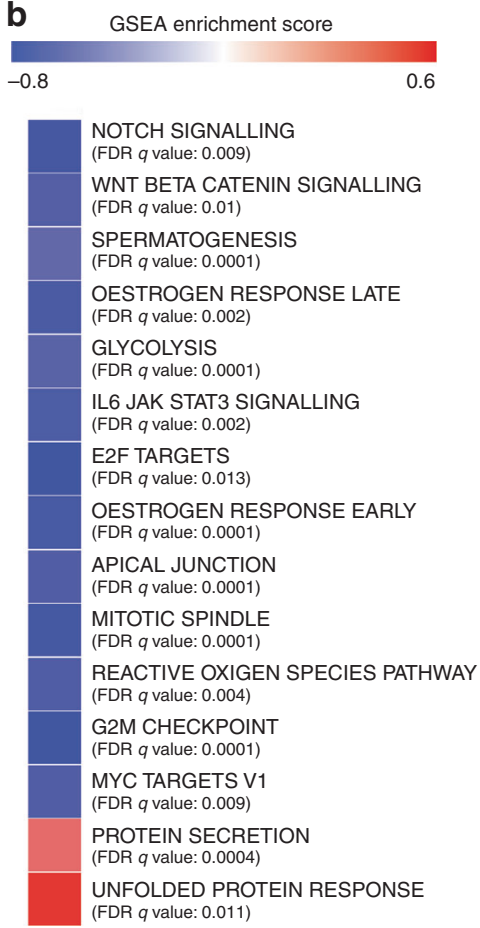

\section{Para-treated cell lines}

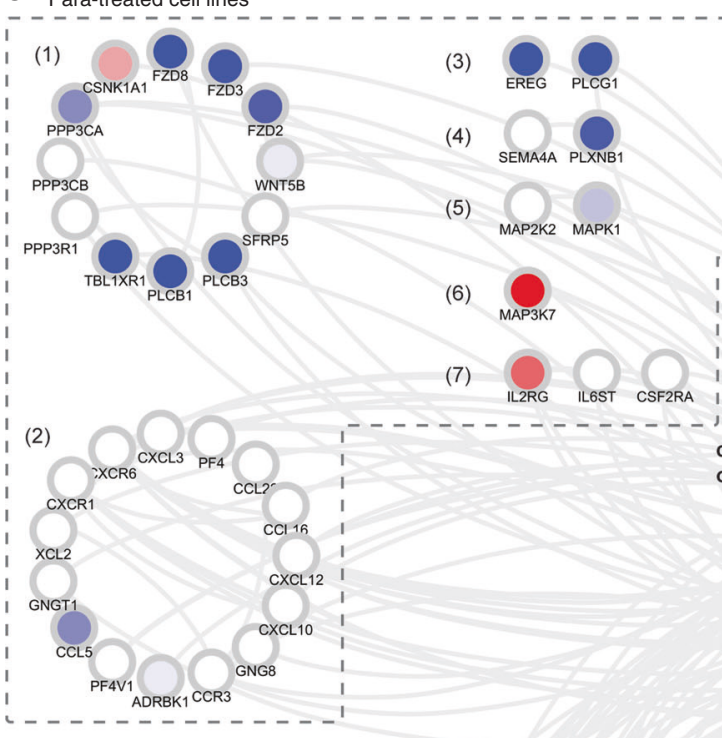

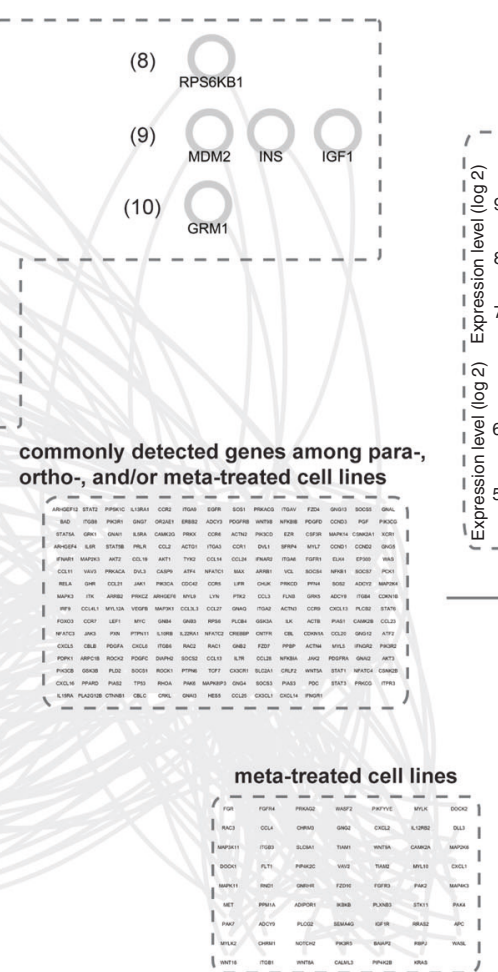

(3) ErbB signalling pathway (8) Insulin signalling pathway
(4) Axon guidance (9) Prostate cancer

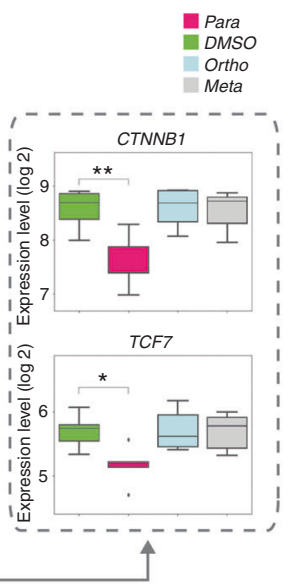

(1) Wnt signalling pathway
(6) MAPK signalling pathway

\begin{abstract}
(2) Chemokine signalling
\end{abstract} (7) Jak-STAT signalling pathway

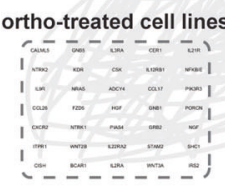

with upregulation of CSNK1A1, might favor survival in GC patients; thus, these genes represent potential GC biomarkers. These findings concur with our results in B16015-para-treated cancer cell lines, showing downregulation of FZD2 and FZD8, and CSNK1A1 upregulation (Fig. 5C), also supporting our survival analysis result (Fig. 6).
Here, based on the above-described findings, in an attempt to understand the potential efficacy of Bl6015, we relocated a nitro group on its benzene ring, from the para position (with regard to a methyl group) to the meta and ortho positions (Fig. 3). We demonstrated that the para compound (i.e., the parental Bl6015) most optimally bound the HNF4a ligand-binding site, via two 
Fig. 5 Para-treated cell lines showed similarly dysregulate gastric cancef (GC) cell line responses at the molecular level. a Transcriptome correlation clustering analysis showed exclusive clustering of the parental para-treated, but not dimethyl sulfoxide (DMSO)-treated, metatreated, or ortho-treated, cell lines, with the latter four clustering only by replicates of individual cell types. As shown, the para-treated cell lines had similarly dysregulated gene expression levels. b Based on the results of the correlation clustering analysis, GSEA analysis was performed, by setting the cell lines treated with para-BI6015 vs. meta-BI6015 and ortho-BI6015 as case groups and control groups, respectively. The top 15 gene sets significantly associated with gene expression differences between case and control groups are shown, specifically revealing the WNT signal pathway. c We merged the three subpathway analyses by our network analysis algorithm, PATHOME, ${ }^{28}$ from ortho- vs. DMSOtreated, vs. meta- vs. DMSO-treated, vs. para- and DMSO-treated cell lines. In the merged subpathway networks, we found not only commonly detected subpathway genes from all three analyses but also treatment-specific subpathway genes. Significantly dysregulated subpathways, including WNT signal pathway genes, uniquely detected in para-BI6015- vs. DMSO-treated cells, are enclosed in the upper left dashed box. Subpathways uniquely detected in other analyses, including ortho- vs. DMSO-treated cells, and meta- vs. DMSO-treated cells, are indicated by the dashed boxes shown at the bottom. Subpathways commonly detected in all three analysis results are shown enclosed in the dashed box in the middle. CTNNB1 and TCF7 were detected as statistically significant in all three para-BI6015-, ortho-BI6015-, and meta-BI6015-treated cell lines; however, they were significantly downregulated only by the para-compound. Positive GSEA scores (red colour) meant that a gene set was enriched in para-compound-treated cell lines, while a negative GSEA score (blue colour) meant that a gene set was enriched in cell lines treated with the other Bl6015 derivatives $\left({ }^{*} p\right.$-value $<0.05,{ }^{* *} p$-value $<0.01$ )

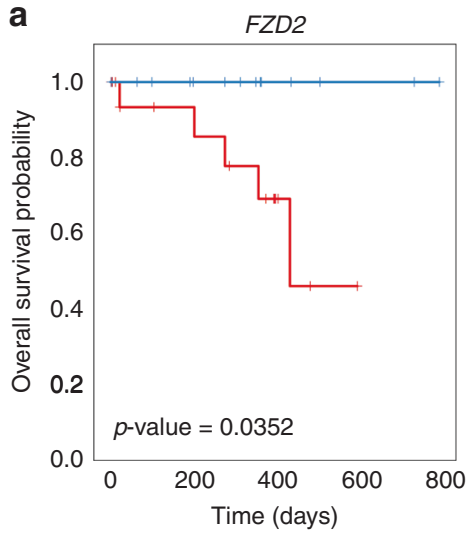

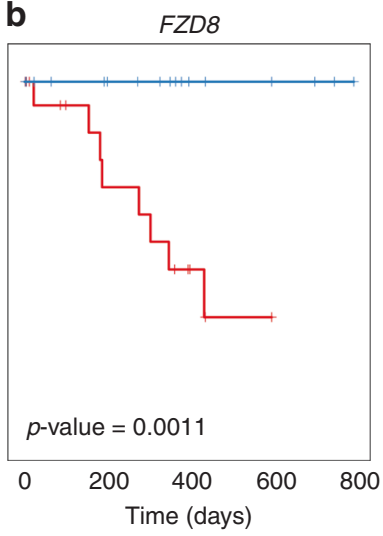

Upper $25 \%$ group
C

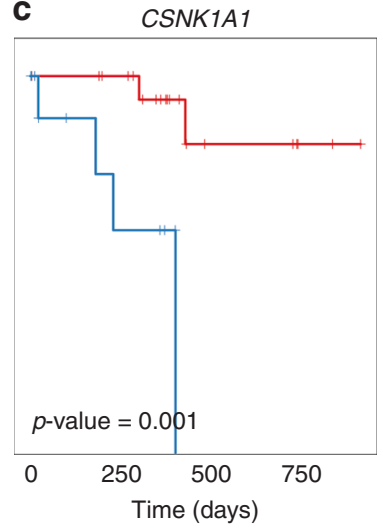

Bottom $25 \%$ group

Fig. 6 FZD2, FZD8, and CSNK1A1, WNT signal pathway genes, were dysregulated by para-Bl6015-treated gastric cancer (GC) cancer cell lines, but divergently influenced patient survival, assessed using a TCGA STAD Asian dataset. The total available number of samples that had survival information and mRNA expression levels in a TCGA STAD dataset was 368 . We calculated the 1 st quantile and the 3 rd quantile of gene expression levels. By using these quantiles for dividing Asian samples $(n=77)$ in the TCGA dataset into two groups, and upper $25 \%$ and bottom $25 \%$ group (see details in the "Survival analysis" section of the Methods). For FZD2, the number of samples in the bottom $25 \%$ group was 16 and that in upper $25 \%$ group was 23 . For FZD8, the sample numbers in the upper $25 \%$ and bottom $25 \%$ groups were 24 and 20 , respectively. For CSNK1A1, the sample numbers in the upper $25 \%$ and bottom $25 \%$ groups were 22 and 14 , respectively. " + " marks show censored patients. $P$ values of survival analysis were derived by the log-rank test

polar (SER181 and ARG226) and one apolar (GLY237) amino acid residues (Figs. 1a, 2). We also demonstrated that para-Bl6015 had the lowest free energy, and the greatest number of ligand structures in its lowest energy cluster, compared to the orthoBl6015 and meta-Bl6015 derivatives (Figs. 1a, 2). Therefore, this result means that Bl6015-para can play a role in inhibiting binding better than the myristic acid, which originally binds HNF4a. ${ }^{20}$ SPR further showed the parent compound (para position) to possess the lowest off-rate $\left(k_{\mathrm{d}}\right)$, dissociation rate $\left(K_{\mathrm{D}}\right)$, and highest on-rate $\left(k_{\mathrm{a}}\right)$, compared to the meta and ortho derivatives (Fig. 3).

In addition to AMPK downregulation of HNF4a, we also reported that this event coincided with repression of the HNF4a target gene, WNT5A, ${ }^{17,18,28}$ in accord with earlier findings of small interfering RNA effects on HNF4a target genes in hamster kidney and ovarian cells. ${ }^{40}$ By examining the transcriptomes of ortho-, meta-Bl6015-, or para-Bl6015-treated cells, we found 23 genes specifically dysregulated by Bl6015 (para), but not its ortho or meta derivatives. We then validated downregulation of WNT activity, as assessed by reporter assays, demonstrating 60 to $\sim 100 \%$ inhibition, in $5 / 6 \mathrm{GC}$ cell lines. Since WNT is a well-known cancer stem cell pathway, its downregulation (i.e., by reduced HNF4a) should also be GC antitumorigenic, and we demonstrated substantial (75 - 95\%) losses of cell viability, and of six diverse GC cell lines, by the parent (para) compound (but not the ortho- derivatives and meta-derivatives) (Fig. 4); we also observed paraBl6150 downregulation of HNF4a in those same cell lines, analogous to a previous study of HepG2 cells. ${ }^{20}$ However, we concede that optimal binding of the para-BI6015 compound, to HNF4a alone, cannot fully explain the antitumour efficacy of the compound, requiring further studies such as subpathway analysis.

It has been contended that subpathway analysis, used to identify highly important "hub" genes within associated networks, might be more biologically meaningful than identifying mere gene sets ${ }^{47}$ or pathway cross-talk. Consequently, we used our PATHOME algorithm to identify distinct para-BI6015-associated subpathways, identifying in particular, the WNT pathway. That finding was in agreement with our current (Fig. 4) and previous ${ }^{17,18,28}$ findings. In future studies, we wish to even more extensively use subpathway analyses, to identify specific mechanisms of HNF4a, and WNT signalling, dysregulation, in GC.

Our top-down, in silico approach used in this study may be applicable to identify modes of mechanism in drug development for other cancer types. Since we revealed that a specific chemical structure disturbs specific cancer cell transcriptomes, in contrast to other materials (i.e., vehicle control or alternate structures), and showed distinct perturbations in gene expression, using clustering analysis. At that juncture, we could narrow down aberrant signalling to several GC cell functional contexts (e.g., WNT and 
Notch signalling pathways) that were dysregulated, based on a functional gene set analysis, GSEA. Moreover, our recent metaanalysis ${ }^{48}$ indicated that WNT5A, belonging to WNT signalling, had positive correlations with lymph node metastasis statuses and tumour depth T stages. Also, high WNT5A expression was significantly associated with Lauren diffused scattered type. ${ }^{48}$ Considering these clinical significances in GC, WNT5A has potential to be developed toward a therapeutic biomarker candidate. Using a subpathway analysis tool, PATHOME, we sought not only perturbed genes but also subpathways impacted by our drug candidate compound, likely expanding our understanding of a possible mode(s) of mechanism. This approach is significantly time-saving and cost-saving, for drug development, in contrast to in vitro and in vivo preclinical strategies.

In conclusion, we have outlined a means of examining specific compounds, biochemically and biologically, for their ability to inhibit the activity of transcription factors, a pursuit that has remained challenging for some time. ${ }^{14-16}$ Although receptor tyrosine kinase inhibitors have demonstrated limited clinical success against gastrointestinal cancers, strategies to target additional diseaseimplicated proteins (e.g., transcription factors) as mono-therapies or multi-therapies represent an additional promising strategy. Finally, this work firmly establishes the role of one particular transcription factor, HNF4a, in GC etiology and progression, supporting our previous extensive work. Targeting either this protein directly or its network-associated genes represents an encouraging approach against this still prevalent and lethal disease. In a broader perspective, we believe that these chemoinformatic and bioinformatic approaches will strongly facilitate the design of "druggable" transcription factor inhibitors, targeting specific oncogenic pathways, in gastric and other liquid and solid tumours.

\section{ACKNOWLEDGEMENTS}

National Research Foundation of Korea (MSIP) 2015R1A2A1A10052661 is acknowledged for funds used to perform the study (Y.H.K.).

\section{AUTHOR CONTRIBUTIONS}

J.-H.K. synthesized the compounds, and J.L., J.-H.K. and G.T.L. performed the docking studies. H.J.E. conducted the biological studies, while S.P. and S.N. conducted gene expression analysis. Y.H.K. and J.-H.J. designed the experiments. J.-H.K., S.P., J.L., S.N., Y.H.K., and J.-H.J. wrote the manuscript. All authors reviewed and approved the manuscript.

\section{ADDITIONAL INFORMATION}

Supplementary information is available for this paper at https://doi.org/10.1038/ s41416-018-0374-5.

Competing interests: The authors declare no competing interests.

Ethics approval and consent to participate: This research studied anonymised information and data sets that have been already publicly available in the wellestablished public domain (The Cancer Genome Atlas in NIH, USA). Therefore, the ethics review was not required.

Data availability: GEO accession GSE114626 deposited.

Publisher's note: Springer Nature remains neutral with regard to jurisdictional claims in published maps and institutional affiliations.

\section{REFERENCES}

1. Siegel, R. L., Miller, K. D. \& Jemal, A. Cancer statistics, 2017. CA Cancer J. Clin. 67, 7-30 (2017).

2. Torre, L. A., Siegel, R. L., Ward, E. M. \& Jemal, A. Global cancer incidence and mortality rates and trends-an update. Cancer Epidemiol. Biomark. Prev. 25, 16-27 (2016).
3. Bollschweiler, E., Berlth, F., Baltin, C., Monig, S. \& Holscher, A. H. Treatment of early gastric cancer in the Western World. World J. Gastroenterol. 20, 5672-5678 (2014).

4. Cristescu, R. et al. Molecular analysis of gastric cancer identifies subtypes associated with distinct clinical outcomes. Nat. Med. 21, 449-456 (2015).

5. Bang, Y. J. et al. Trastuzumab in combination with chemotherapy versus chemotherapy alone for treatment of HER2-positive advanced gastric or gastrooesophageal junction cancer (ToGA): a phase 3, open-label, randomised controlled trial. Lancet 376, 687-697 (2010).

6. Iqbal, S. et al. Southwest Oncology Group study S0413: a phase II trial of lapatinib (GW572016) as first-line therapy in patients with advanced or metastatic gastric cancer. Ann. Oncol. 22, 2610-2615 (2011).

7. Lordick, F. et al. Capecitabine and cisplatin with or without cetuximab for patients with previously untreated advanced gastric cancer (EXPAND): a randomised, open-label phase 3 trial. Lancet Oncol. 14, 490-499 (2013).

8. Zhan, T., Rindtorff, N. \& Boutros, M. Wnt signaling in cancer. Oncogene 36, 1461-1473 (2017).

9. Polk, D. B. \& Peek, R. M. Jr. Helicobacter pylori: gastric cancer and beyond. Nat. Rev. Cancer 10, 403-414 (2010).

10. Takahashi-Yanaga, F. \& Kahn, M. Targeting Wnt signaling: can we safely eradicate cancer stem cells? Clin. Cancer Res. 16, 3153-3162 (2010).

11. Takebe, N. et al. Targeting Notch, Hedgehog, and Wnt pathways in cancer stem cells: clinical update. Nat. Rev. Clin. Oncol. 12, 445-464 (2015).

12. Anastas, J. N. Functional crosstalk between WNT signaling and tyrosine kinase signaling in cancer. Semin. Oncol. 42, 820-831 (2015).

13. Song, L., Li, Z. Y., Liu, W. P. \& Zhao, M. R. Crosstalk between Wnt/beta-catenin and Hedgehog/Gli signaling pathways in colon cancer and implications for therapy. Cancer Biol. Ther. 16, 1-7 (2015).

14. Darnell, J. E. Jr. Transcription factors as targets for cancer therapy. Nat. Rev. Cancer 2, 740-749 (2002).

15. Dunker, A. K. \& Uversky, V. N. Drugs for 'protein clouds': targeting intrinsically disordered transcription factors. Curr. Opin. Pharmacol. 10, 782-788 (2010).

16. Yeh, J. E., Toniolo, P. A. \& Frank, D. A. Targeting transcription factors: promising new strategies for cancer therapy. Curr. Opin. Oncol. 25, 652-658 (2013).

17. Chang, H. R. et al. HNF4alpha is a therapeutic target that links AMPK to WNT signalling in early-stage gastric cancer. Gut 65, 19-32 (2016).

18. Kim, Y. H. et al. AMPKalpha modulation in cancer progression: multilayer integrative analysis of the whole transcriptome in Asian gastric cancer. Cancer Res. 72, 2512-2521 (2012).

19. Kiselyuk, A. et al. Phenothiazine neuroleptics signal to the human insulin promoter as revealed by a novel high-throughput screen. J. Biomol. Screen. 15 663-670 (2010).

20. Kiselyuk, A. et al. HNF4alpha antagonists discovered by a high-throughput screen for modulators of the human insulin promoter. Chem. Biol. 19, 806-818 (2012).

21. Moyna, G., Hernandez, G., Williams, H. J., Nachman, R. J. \& Scott, A. I. Development of Weiner et al. force field parameters suitable for conformational studies of [1,4]benzodiazepines and related compounds. J. Chem. Inf. Comput. Sci. 37, 951-956 (1997).

22. Rha, G. B., Wu, G., Shoelson, S. E. \& Chi, Y. I. Multiple binding modes between HNF4alpha and the LXXLL motifs of PGC-1alpha lead to full activation. J. Biol. Chem. 284, 35165-35176 (2009).

23. Spitzer, R. \& Jain, A. N. Surflex-Dock: docking benchmarks and real-world application. J. Comput. Aided Mol. Des. 26, 687-699 (2012).

24. Trott, O. \& Olson, A. J. AutoDock Vina: improving the speed and accuracy of docking with a new scoring function, efficient optimization, and multithreading. J. Comput. Chem. 31, 455-461 (2010).

25. Brooks, B. R. et al. CHARMM: the biomolecular simulation program. J. Comput. Chem. 30, 1545-1614 (2009).

26. Saldanha, A. J. Java Treeview-extensible visualization of microarray data. Bioinformatics 20, 3246-3248 (2004).

27. Hung, J. H., Yang, T. H., Hu, Z., Weng, Z. \& DeLisi, C. Gene set enrichment analysis: performance evaluation and usage guidelines. Brief Bioinform. 13, 281-291 (2012)

28. Nam, S. et al. PATHOME: an algorithm for accurately detecting differentially expressed subpathways. Oncogene 33, 4941-4951 (2014).

29. Kanehisa, M. \& Goto, S. KEGG: Kyoto Encyclopedia of Genes and Genomes. Nucleic Acids Res. 28, 27-30 (2000).

30. Shannon, P. et al. Cytoscape: a software environment for integrated models of biomolecular interaction networks. Genome Res. 13, 2498-2504 (2003).

31. Cancer Genome Atlas Research N. Comprehensive molecular characterization of gastric adenocarcinoma. Nature 513, 202-209 (2014).

32. Zhu, J. et al. The UCSC Cancer Genomics Browser. Nat. Methods 6, 239-240 (2009).

33. Cerami, E. et al. The cBio cancer genomics portal: an open platform for exploring multidimensional cancer genomics data. Cancer Discov. 2, 401-404 (2012). 
Differential effects, on oncogenic pathway signalling, by derivatives of... J.-H. Kim et al.

498

34. Mantel, N. Evaluation of survival data and two new rank order statistics arising in its consideration. Cancer Chemother. Rep. 50, 163-170 (1966).

35. Lipinski, C. A. Drug-like properties and the causes of poor solubility and poor permeability. J. Pharmacol. Toxicol. Methods 44, 235-249 (2000).

36. Yalkowsky, S. H. \& Valvani, S. C. Solubility and partitioning I: solubility of nonelectrolytes in water. J. Pharm. Sci. 69, 912-922 (1980).

37. Alexander, S. P. et al. The concise guide to pharmacology 2017/18: nuclear hormone receptors. Br. J. Pharmacol. 174(Suppl. 1), S208-S224 (2017).

38. Chang, H. R. et al. Systematic approach identifies RHOA as a potential biomarker therapeutic target for Asian gastric cancer. Oncotarget 7, 81435-81451 (2016).

39. Lim, B., Kim, J. H., Kim, M. \& Kim, S. Y. Genomic and epigenomic heterogeneity in molecular subtypes of gastric cancer. World J. Gastroenterol. 22, 1190-1201 (2016).

40. Hong, Y. H., Varanasi, U. S., Yang, W. \& Leff, T. AMP-activated protein kinase regulates HNF4alpha transcriptional activity by inhibiting dimer formation and decreasing protein stability. J. Biol. Chem. 278, 27495-27501 (2003).

41. Leclerc, I. et al. Hepatocyte nuclear factor-4alpha involved in type 1 maturityonset diabetes of the young is a novel target of AMP-activated protein kinase. Diabetes 50, 1515-1521 (2001).

42. Miura, A. et al. Hepatocyte nuclear factor-4alpha is essential for glucosestimulated insulin secretion by pancreatic beta-cells. J. Biol. Chem. 281, 5246-5257 (2006).

43. Bian, Y. et al. Promotion of epithelial-mesenchymal transition by Frizzled 2 is involved in the metastasis of endometrial cancer. Oncol. Rep. 36, 803-810 (2016).

44. Gupta, S. et al. FZD4 as a mediator of ERG oncogene-induced WNT signaling and epithelial-to-mesenchymal transition in human prostate cancer cells. Cancer Res. 70, 6735-6745 (2010).
45. Schneider, R. K. et al. Role of casein kinase $1 \mathrm{~A} 1$ in the biology and targeted therapy of del(5q) MDS. Cancer Cell 26, 509-520 (2014).

46. Sinnberg, T., Wang, J., Sauer, B. \& Schittek, B. Casein kinase 1alpha has a nonredundant and dominant role within the CK1 family in melanoma progression. BMC Cancer 16, 594 (2016).

47. Li, X., Shen, L., Shang, X. \& Liu, W. Subpathway analysis based on signalingpathway impact analysis of signaling pathway. PLOS ONE 10, e0132813 (2015).

48. Nam, S., Chung, J. W. \& Yang, J. Y. WNT5A correlates with clinicopathological characteristics in gastric cancer: a meta-analysis. Cell. Physiol. Biochem. 41, 33-40 (2017).

(i) Open Access This article is licensed under a Creative Commons adaptation, distribution and reproduction in any medium or format, as long as you give appropriate credit to the original author(s) and the source, provide a link to the Creative Commons license, and indicate if changes were made. The images or other third party material in this article are included in the article's Creative Commons license, unless indicated otherwise in a credit line to the material. If material is not included in the article's Creative Commons license and your intended use is not permitted by statutory regulation or exceeds the permitted use, you will need to obtain permission directly from the copyright holder. To view a copy of this license, visit http://creativecommons. org/licenses/by/4.0/.

(c) The Author(s) 2019 